\title{
Da objetividade à intersubjetividade: contribuições da teoria do Agir Comunicativo para o paradigma Interpretativo
}

\section{From objectivity to the intersubjectivity: contributions of Theory of Communicative Action to the Interpretive Paradigm}

\author{
Hernani Luiz Azevedo* \\ Universidade Federal de Mato Grosso \\ Gladys Denise Wielewski** \\ Universidade Federal de Mato Grosso
}

Resumo O presente artigo traz algumas discussões sobre a relação objetividade/ subjetividade na construção do conhecimento, tendo em vista o $\mathrm{Pa}-$ radigma Interpretativo, muito utilizado nas pesquisas qualitativas em educação e educação científica. Para tanto, discorremos sobre alguns paradigmas epistemológicos presentes na ciência e filosofia, como o paradigma positivista e o fenomenológico. A evolução histórica dos debates sobre a influência da subjetividade na construção do conhecimento nos levou a prestar especial atenção à Teoria do Agir Comunicativo, de Jürgen Habermas, tendo em vista a centralidade da intersubjetividade presente nesta teoria. Concluímos o texto explicitando como desse debate se fez emergir uma teoria da racionalidade humana.

PALAVRAS-CHAVE: Pesquisa qualitativa; Intersubjetividade; Teoria do Agir Comunicativo.

Abstract This article presents some discussions about the issue of objectivity/ subjectivity in the construction of knowledge, in view of the Interpretive Paradigm, widely used in research about education and about science education. For this, we approach some epistemological paradigms present in science and philosophy, as the positivist paradigm and the phenomenological. The historical evolution of discussions on the influence of subjectivity in the genesis of knowledge has led us to pay special attention to the Theory of Communicative Action, of Jürgen Habermas, in view of the centrality that intersubjectivity has in this theory. We conclude the text explaining how this debate brings out a theory of human rationality.

KEYWORDS: Qualitative research; Intersubjectivity; Theory of Communicative Action. 


\section{Introdução}

Quando indagadas sobre as características do conhecimento científico, uma das características mais citadas como resposta pelas pessoas em nossa sociedade é a objetividade da ciência, adquirida por meio de rigorosa e metódica experimentação (PEREIRA e ARAÚJO, 2010). Segundo essa concepção popular, o conhecimento científico seria 'objetivo' pois seria preciso, verificável e independente de preferências pessoais de qualquer tipo. Em outras palavras, o conhecimento científico seria isento de influências subjetivas.

Tal concepção presente em nossa sociedade é em grande parte herança de uma concepção positivista de ciência. O positivismo, uma tradição filosófica fundada por Auguste Comte (1798-1857), via o conhecimento científico como o mais depurado conhecimento produzido pelo intelecto humano. Segundo Comte, o pensamento humano estaria fadado a passar por três estágios sucessivos: nos dois primeiros deles (estado teológico e estado metafísico) existiria um alto teor de devaneios da mente humana (subjetividade) e no terceiro estágio (o estágio positivo, donde positivismo) o conhecimento se revelaria em um patamar mais elevado que os anteriores, no qual a atenção humana se voltaria apenas às relações observáveis (objetivas) de causa e efeito:

Enfim, no estado positivo, o espírito humano, reconhecendo a impossibilidade de obter noções absolutas, renuncia a procurar a origem e o destino do Universo, a conhecer as causas íntimas dos fenômenos, para preocupar-se unicamente em descobrir, graças ao uso bem combinado do raciocínio e da observação, suas leis efetivas, a saber, suas relações invariáveis de sucessão e de similitude (COMTE, 1973, p. 10).

Para o pensamento positivista, o aumento do conhecimento científico traria como consequência o progresso humano, um estado de redenção e liberdade não oportunizado por outros tipos de conhecimentos. $\mathrm{Na}$ visão positivista, inclusive, qualquer outro tipo de conhecimento deveria se submeter ao empirismo científico, o único com a prerrogativa de emitir vereditos quanto à verdade ou falsidade de alguma proposição:

Para o positivismo, as sentenças que não puderem ser verificadas empiricamente estariam fora da fronteira do conhecimento: seriam sentenças sem sentido. [...]. A verificabilidade seria, portanto, o critério de significação de um enunciado; para todo enunciado com sentido deveria ser possível decidir se ele é falso ou verdadeiro (ALVES-MAZZOTTI; GEWANDSZNAJDER, 2001, p. 12).

Esta pretensa objetividade e impessoalidade é atribuída ao conhecimento científico, segundo os positivistas, graças à utilização do método científico. Segundo Gamboa, "toda investigação supõe um corpo teórico, e deve ter um método que lhe seja apropriado" e "o conhecimento é o resultado da relação entre um sujeito cognoscente e um objeto a ser conhecido" (GAMBOA, 2012, p. 43 e p. 45). Assim, a abordagem positivista ancora-se no método científico, privilegiando o fato ou objeto, eclipsando o sujeito cognoscente. Esta abordagem supõe ainda que o objeto do conhecimento não interage com o sujeito, de maneira a não existir uma influência mútua (Ibid., p. 45). 
No entanto, durante o século XX essa superioridade do conhecimento científico pregada pelos positivistas foi contestada pela filosofia da ciência. Autores como Thomas Kuhn, Karl Popper, Imre Lakatos e Paul Feyerabend contestaram muitas das idealizações positivistas quanto à natureza da ciência. Dentre os pontos levantados por estes filósofos se encontrava o fato das asserções científicas não serem temporalmente imutáveis (KUHN, 2007), ou seja, o conhecimento apontado como cientificamente correto hoje pode não ser necessariamente o que será apontado como verdadeiro amanhã. Popper salientou que o raciocínio indutivo presente no método científico é carregado de uma grande dose de suposição (POPPER, 2007). Feyerabend também criticou veementemente o método científico, salientando que, historicamente, muitos dos avanços científicos ocorreram justamente quando os cientistas deixaram de lado o procedimento indicado pelo "método científico" e adotaram algum procedimento novo, não convencional (FEYERABEND, 2011). Lakatos negou uma total objetividade científica ao afirmar que muitas das escolhas feitas na ciência são tomadas devido a fatores subjetivos, como preferências pessoais dos cientistas (LAKATOS, 1979).

Também no início do século XX, filósofos como Edmund Husserl (18591938) já deslumbravam a necessidade de uma forma alternativa de se conceber a relação entre sujeito e objeto para além do método analítico-dedutivo utilizado pelas ciências naturais. Husserl formulou uma teoria filosófica que visava apreender a essência absoluta das coisas, e para tanto os fenômenos deveriam ser conhecidos segundo o ponto de vista mental de cada indivíduo, ou seja, precisava-se conhecer como os fenômenos são percebidos pelas pessoas (CHAUÍ, 2006). Nascia a assim a fenomenologia:

Mas aqui é necessário, para o nosso problema da crise, mostrar como é possível que a época moderna, durante séculos tão orgulhosa de seus êxitos teóricos e práticos, tenha caído ela mesma numa crescente insatisfação e que ainda deve experimentar sua situação como situação de penúria. Em todas as ciências se insinua essa penúria, em última análise, como penúria do método. [...] Trata-se de problemas procedentes da ingenuidade, em virtude da qual a ciência objetivista toma o que ela chama o mundo objetivo como sendo o universo de todo o existente, sem considerar que a subjetividade criadora da ciência não pode ter seu lugar legítimo em nenhuma ciência objetiva. Aquele que é formado nas ciências naturais julga evidente que todos os fatores puramente subjetivos devem ser excluídos e que o método científico-natural determina, em termos objetivos, o que tem sua figuração nos modos subjetivos da representação (HUSSERL, 2002, p. 60).

Para Husserl, as ciências naturais se debruçariam sobre as relações de causa e efeito das estruturas físicas, mas tais ciências não poderiam debruçar-se sobre si mesmas, investigando sua própria natureza. Esta seria tarefa de uma filosofia transcendental. Husserl chama de fenomenologia esta última instância da filosofia, que seria a ciência dos fundamentos últimos, o conhecimento das essências. Tal conhecimento só poderia revelar-se colocando em evidência as experiências da consciência, ou seja, buscando os significados presentes nas mentes dos indivíduos.

Foi Husserl que cunhou o termo "mundo da vida" (mais tarde utilizado e modificado por Habermas, como veremos logo mais) para expressar a necessidade 
da existência de uma estrutura de entendimento para além do mundo físico, mundo físico este tido como o único existente e apto a ser estudado segundo o cientificismo associado à razão instrumental.

Husserl apresenta-nos o conceito de mundo da vida no contexto de uma crítica da razão. Partindo de um ponto subjacente à realidade que as ciências naturais assumem como sendo a única, afasta-se do já existente contexto das práticas de vida pré-refletidas e da experiência do mundo como a fundação destituída de significado. A este nível, o mundo da vida representa o conceito oposto daquelas idealizações que constituem em primeiro lugar o objeto das ciências naturais. Em oposição às idealizações da medição, causalidade imputada e matematização, bem como à tendência para a utilização de mais tecnologias operativas no seio das mesmas, Husserl procura recuperar o mundo da vida como o reino imediatamente presente dos feitos originários. Da perspectiva deste mundo da vida, critica as idealizações ignorantes da sua própria existência - do objetivismo científico natural (HABERMAS, 2002, p. 129).

Habermas irá inspirar-se no conceito de mundo da vida de Husserl para identificar em sua Teoria do Agir Comunicativo a estrutura onde deveriam ocorrer os diálogos e o entendimento entre os seres humanos, estrutura esta que estaria sendo colonizada pela racionalidade técnica, impedindo que a comunicação e o entendimento venham ocorrer de forma adequada entre as pessoas.

Assim, a subjetividade intrínseca às percepções pessoais e as características próprias dos sujeitos passaram a ser devidamente incorporadas à análise das interações entre os sujeitos das pesquisas, acrescentando alternativas ao antigo paradigma sujeito/ objeto de se admitir a interação entre os entes envolvidos na construção do conhecimento. Esta epistemologia mais interativa está associada a paradigma interpretativo. Andrade e Tanaka definem assim paradigma interpretativo:

O paradigma interpretativo, subjetivista, orienta-se pela tentativa de compreender o mundo tal como ele é percebido e vivido; compreender a natureza fundamental do mundo social, ao nível da experiência subjetiva. Procura explicações no terreno da consciência individual e da subjetividade, na perspectiva dos participantes e não na dos observadores da ação. Tem como representantes maiores Dilthey, Weber, Husserl, Schutz, Heidegger, Wittgenstein e Gadamer (ANDRADE; TANAKA, 2001, p.60, grifo no original).

Como exemplos de metodologias que utilizam o paradigma interpretativo podemos citar a fenomenologia, o interacionismo simbólico e a etnometodologia.

Toda esta discussão sobre as premissas epistemológicas que antecedem a aquisição de conhecimento não são estranhas à pesquisa em educação, tampouco à pesquisa em educação científica. Segundo Gamboa, neste tipo particular de pesquisa também sempre estão presentes as seguintes pressuposições: a primazia do objeto ou do sujeito, ou mesmo a ênfase da relação entre eles; a consideração ou não de recortes ou rupturas do objeto em relação ao seu contexto; e a compreensão do objeto do conhecimento como um todo e sua articulação com suas partes constituintes (GAMBOA, 2012, p. 138). 
Deste modo, as questões relativas à interpretação de significados ganham destaque também na pesquisa em educação científica. Pérez Gómez, tratando sobre pesquisa educativa, sustenta que:

Para compreender a complexidade real dos fenômenos educativos como fenômeno social, é imprescindível chegar aos significados compartilhados pelos grupos, comunidades e culturas. A complexidade da investigação educativa reside precisamente nesta necessidade de ter acesso aos significados, já que estes só podem ser captados de modo situacional, no contexto dos indivíduos que os produzem e trocam (PÉREZ GÓMEZ, 1998, p. 103).

Fica evidente, para uma real compreensão dos fenômenos educacionais, a importância do acesso aos significados partilhados pelos participantes da esfera educativa. Mas, como ter acesso a estes significados? Como pode se dar esse compartilhamento de percepções acerca dos fenômenos educacionais?

Para entender melhor a profundidade dessas questões no que tange a esta troca de significados, precisaremos nos enveredar por algumas características da comunicação, a fim de entender como se dá a compreensão mútua entre dois comunicantes. Para tanto, neste artigo, faremos uso da Teoria do Agir Comunicativo, a qual se insere dentro do amplo paradigma interpretativo em virtude do destacado papel que a interpretação dos significados das expressões desempenha nesta teoria da racionalidade:

Para esta última [racionalidade comunicativa], deixa de ser paradigmática a relação que o sujeito isolado mantém com alguma coisa apresentável e manipulável no mundo, e passa a ser paradigmática a relação intersubjetiva assumida por sujeitos aptos a falar e agir, quando se entendem uns com os outros sobre alguma coisa. Para tanto, os que agem de maneira comunicativa movimentam-se no medium de uma linguagem natural e fazem uso de interpretaçóes legadas pela tradição [grifo nosso], ao mesmo tempo que se referem a alguma coisa no mundo objetivo único, em seu mundo social partilhado, e no respectivo mundo subjetivo. (HABERMAS, 2012, p. 674).

Delinearemos nos tópicos seguintes a Teoria do Agir Comunicativo, tentando explicitar o papel da cultura (tradição) nas relações interpretativas. Começaremos lembrando um importante momento de transição dentro da Filosofia.

\section{Do paradigma da consciência ao da linguagem}

Pode-se dizer que desde o início da modernidade no final do século XVI até o início do século XX a maior parte das reflexões filosóficas centrou-se no paradigma da consciência (ou filosofia da consciência). Tal paradigma fazia a filosofia girar em torno de questões acerca da racionalidade humana: qual a fonte das ideias humanas? Como a mente humana vem a adquirir conhecimento? Neste paradigma, a razão humana e o modo de validação de proposições estavam centradas no sujeito cognoscente. A famosa colocação de Descartes "Penso, logo existo" pode ser considerado um bom exemplo da ênfase da temática pertencente a este paradigma. A natureza poderia ser estudada por tal sujeito numa relação sujeito/objeto não muito problemática. $\mathrm{O}$ conhecimento adquirido poderia ser representado e transmitido nos mesmos termos. Nas palavras de Habermas: 
Pensou-se que se poderia explicar a relação do significado com o significante (o signo) com base na relação do símbolo (o signo portador de significado) com o designado (o objeto significado). Esta noção semiótica básica adequava-se à teoria do conhecimento centrada no objeto, proposta pela filosofia da consciência (HABERMAS, 2002, p. 154).

No início do século XX, no entanto, houve uma reviravolta na atenção de uma parcela dos filósofos, que passaram a dedicar atenção para aspectos essenciais da linguagem e comunicação humana. Essa mudança ficou conhecida como "guinada linguística" ou "virada linguística" da filosofia, cujo principal nome geralmente associado a ela é Ludwig Wittgenstein. Tal mudança se deu, grosso modo, pela observação que só temos acesso às ideias, aos conceitos, sejam eles científicos, filosóficos, ou de qualquer natureza por meio da linguagem. Deslocou-se o foco do paradigma da consciência na medida em que se reconheceu o papel fundamental da linguagem na racionalidade humana: somente pela mediação de signos racionalmente ordenados é que temos acesso a qualquer conceito ou ideia.

Habermas faz uso de um modelo de Bühler (HABERMAS, 2002) para discutir essa característica que faz da linguagem o canal de acesso entre quaisquer comunicantes:

Figura 1: Esquema das funções da linguagem de Bühler (HABERMAS, 2002, p. 149).

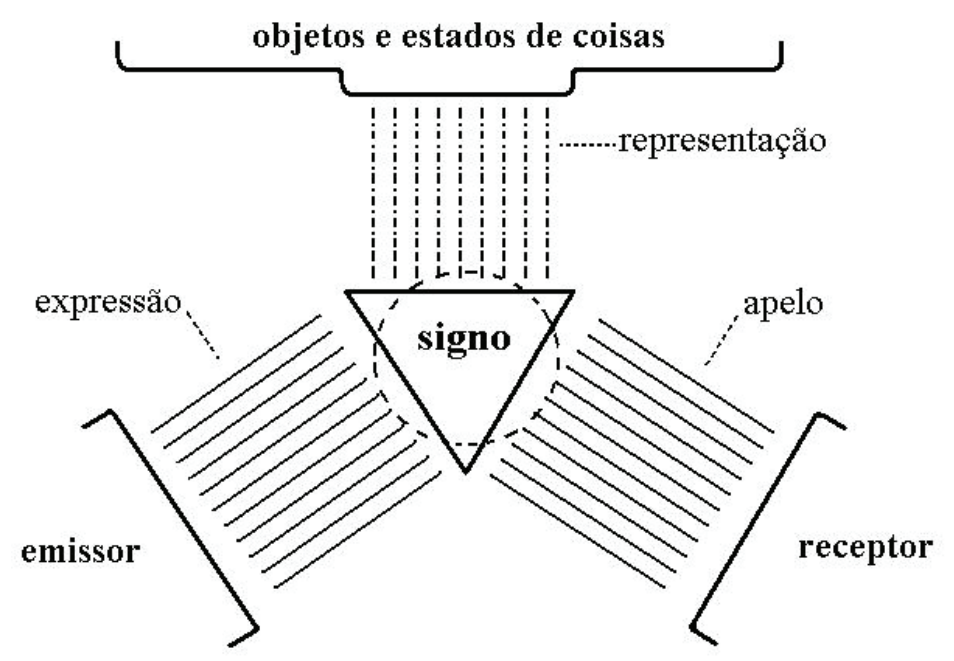

Foge ao escopo deste artigo fazer uma análise mais acurada de todas as características do modelo da linguagem de Bühler. Sublinharemos aqui apenas sua proposição básica: a função dos signos (elementos que formam a linguagem) é fazer a mediação entre (1) os objetos ou estados de coisas no mundo (representação) e (2) as ideias provenientes de qualquer outra pessoa (expressão). No entanto, o que este signo irá significar para o receptor dependerá do apelo que este signo produz no receptor, apelo este que dependerá de características internas do receptor (história de vida, sentimentos, etc.) e, portanto, o significado do signo estará sujeito a fatores ditos subjetivos. 


\section{Do paradigma da linguagem ao Agir Comunicativo}

Assim, fatores pessoais e culturais estão sempre presentes na interpretação de qualquer signo, qualquer enunciado, em qualquer idioma. Aliás, aprender qualquer idioma já é uma tentativa de interpretação de significados de formas de vida específicas.

Aprender a dominar uma língua ou aprender a forma como as expressões de uma determinada língua deveriam ser compreendidas exige habituação a uma forma de vida. Esta última regula antecipadamente a utilização de palavras e frases numa rede de finalidades e ações possíveis (HABERMAS, 2002, p. 156).

Estas formas de vida específicas que regulam o entendimento do significado dos signos fazem parte do que Habermas chama de mundo da vida. Nesta estrutura (que divide-se em três partes) que os interlocutores buscariam suas interpretações e lançariam suas pretensões de validade (emissão de frases com o intuito destas serem compreendidas e aceitas pelos demais), ou seja, o mundo da vida é a estrutura na qual se dá (ou deveria ocorrer) a comunicação e o entendimento entre as pessoas.

O mundo da vida seria dividido em três partes: cultura, sociedade e estruturas de personalidade (HABERMAS, 2002, p. 139). Cultura seria a reserva de conhecimento no qual os comunicantes, ao tentarem se entender, vão buscar as suas interpretações. Sociedade seriam as ordens legitimamente constituídas das quais os comunicantes se reconhecem participantes e nas quais promovem uma relação de solidariedade. Por fim, nas estruturas de personalidade estariam todas as motivações e capacidades de um comunicante que o caracterizam como indivíduo. Nas palavras de Habermas:

Podemos agora imaginar as componentes do mundo da vida - paradigmas culturais, ordens legítimas e estruturas pessoais - como formas condensadas dos (e sedimentos depositados pelos) seguintes processos que operam através da ação comunicativa: entendimento, coordenação da ação e socialização. [...] A rede de práticas comunicativas cotidianas estende-se pelo campo semântico dos conteúdos simbólicos da mesma forma que nas dimensões do espaço social e do tempo histórico, constituindo o meio através do qual a cultura, a sociedade e as estruturas de personalidade se desenvolvem e se reproduzem (HABERMAS, 2002, p. 139).

As componentes do mundo da vida não são estáticas, mas modificam-se e reproduzem-se de acordo com a qualidade das comunicações que ocorrem dentro do mundo da vida. Em especial, devemos atentar para a propriedade não estática da cultura, que serve tanto como fonte de recursos semânticos para os comunicantes, como vai sendo permanentemente modificada no jogo das interpretações que ocorrem cada vez que um signo da linguagem é proferido e captado:

O conteúdo das tradições culturalmente transmitidas de geração em geração é sempre um conhecimento adquirido por pessoas. Sem a apropriação hermenêutica e o posterior desenvolvimento do conhecimento cultural através das pessoas, nenhuma tradição pode progredir ou ser mantida. Neste sentido, as pessoas alcançam algo para a cultura através dos seus feitos interpretativos. No entanto, a cultura (por 
seu turno) representa também ela um recurso para as pessoas [...]. Toda a tradição cultural é simultaneamente um processo de educação (Bildung) para os sujeitos capazes de discurso e ação que são formados no seu seio, da mesma forma que estes, por seu turno, mantém a cultura viva (HABERMAS, 2002, p. 144).

Neste movimento, podemos perceber o quanto a subjetividade proveniente das interpretações vai modificando a cultura e esta modificando as interpretações numa via de mão dupla. Toda essa permanente transformação ocorre porque essas informações vão sendo transmitidas por meio do canal da linguagem. Cabe aqui, portanto, uma diferenciação entre informações advindas de experiências sensórias e as mediadas pela linguagem. Segundo Habermas, surge uma grande diferença entre um conhecimento empírico-analítico e os reconstrutivos, na medida em que o primeiro se baseia em experiência sensória (ou observação) e o segundo numa experiência comunicativa (ou entendimento) (HABERMAS, 2002, p. 22). Enquanto o primeiro é dirigido para objetos e acontecimentos perceptíveis, o segundo é dirigida para o significado das expressões:

Ao experimentar, o observador encontra-se em princípio só [...]. Pelo contrário, o intérprete que compreende o significado passa pelas suas experiências fundamentalmente enquanto participante na comunicação, numa relação intersubjetiva [grifo nosso] estabelecida através de símbolos com outros indivíduos, mesmo que na realidade se encontre só, lendo [...] (HABERMAS, 2002, p. 22).

Chega-se ao nó górdio neste ponto: a busca pelo acesso às concepções e ideias presentes na mente de uma outra pessoa (ou seja, tentar manter uma relação intersubjetiva) só é possível por meio da comunicação (e esta fazendo uso dos signos da linguagem). Mas uma comunicação só é efetiva se os comunicantes compreenderem o que os demais estão falando, ou seja, se houver entendimento entre eles em relação ao que se está sendo falado. As interações comunicativas só se iniciam e progridem na medida em que se reconhece um ponto de consenso ou concordância entre os comunicantes. "O objetivo de se conseguir um entendimento é chegar-se a uma concordância que termine na mutualidade intersubjetiva de compreensão recíproca, no conhecimento partilhado" (Ibid., p. 12). Trocando em miúdos: a compreensão entre dois comunicantes se inicia quando, em algum momento, eles concordam em relação a alguma coisa: "Simplesmente não saberíamos o que é compreender o significado de uma expressão se não soubéssemos que a mesma pode e deve servir para gerar um acordo" (Ibid., p.174).

Percebemos assim que os atos de fala estão intrinsecamente orientados para o entendimento, isto é, para uma concordância racionalmente motivada a respeito daquilo que é dito. Evidentemente, esse acordo pode não surgir de imediato. Antes das colocações ganharem a concordância dos comunicantes elas são somente pretensões de validade: atos de fala que carregam um conteúdo que se apresenta para apreciação dos comunicantes, que devem se posicionar quanto a esse conteúdo. Essas pretensões de validade são sempre criticáveis, de modo que outro elemento chave da teoria habermasiana é a argumentação presente nas interações comunicativas. 
Com a sua pretensão de validade, o falante apela a uma reserva de potenciais razões que poderiam ser aduzidas para o apoiar. As razões interpretam as condições de validade e, nesta medida, fazem também elas parte das condições que tornam um enunciado aceitável (HABERMAS, 2002, p. 173).

Desta forma, a racionalidade comunicativa vislumbrada por Habermas não coaduna-se com perspectivas solipsistas ou completamente relativistas da realidade (OFFREDI, 2006, p. 27), uma vez que o agir comunicativo busca justamente elementos comuns presentes nas diferentes visões de mundo para formar o arcabouço das asserções que constituiriam a realidade (ainda que a verdade assim construída não seja necessariamente imutável: as proposições antes aceitas sempre são passíveis de crítica e podem vir a deixar de serem aceitas).

Por fim, para que estes enunciados sejam considerados não apenas aceitáveis, mas para que possam gozar do predicado "racionais" (pois, assim como os filósofos da modernidade, Habermas intentou formular uma teoria da racionalidade humana) as condições de produção dos atos de fala (tanto as pretensões de validade como as respectivas críticas) devem ser guiados por quatro normas de vigência obrigatória (HABERMAS, 2007a, p. 57) que definem as expectativas recíprocas de comportamento e que tem de ser entendidas e reconhecidas pelos sujeitos comunicantes. Essas condições, essenciais para a manutenção de um agir comunicativo (donde Teoria do Agir Comunicativo) podem ser assim enunciadas:

a) Inclusividade: nenhuma pessoa capaz de dar uma contribuição relevante pode ser excluída da participação.

b) Distribuição simétrica das liberdades comunicativas: todos devem ter a mesma chance de fazer contribuições.

c) Condição de franqueza: o que é dito pelos participantes têm de coincidir com o que pensam.

d) Ausência de constrangimentos externos ou que residem no interior da estrutura da comunicação: os posicionamentos na forma de "sim" ou "não" dos participantes quanto a pretensões de validade, criticáveis, têm de ser motivados pela força de convicção de argumentos convincentes (HABERMAS, 2007b, p. 97).

Assim, a questão da validade das sentenças (que não pode ser verificada diretamente como pretendia a filosofia da consciência, em virtude do não acesso direto à essência das coisas sem a mediação de qualquer indivíduo) poderia ser deduzida da condução de situações ideais de comunicação, nas quais a produção das sentenças satisfaçam as condições pragmáticas apresentadas.

\section{Considerações finais}

Começamos este artigo apresentando o ideal de objetividade na aquisição do conhecimento almejado pela filosofia positivista, que seria alcançado segundo uma metodologia puramente empírico-analítica. Apontamos que filósofos do século XX 
foram enfáticos ao desacreditar tal ideal de objetividade, salientando a incompletude de uma visão puramente cientificista de realidade. Relatamos que tal tendência levou a adoção de uma perspectiva epistemológica que não desprezasse a subjetividade presente no espírito humano, e chamamos esta perspectiva de paradigma interpretativo. Chamamos a atenção para a importância do paradigma interpretativo para a compreensão dos fenômenos educacionais, tendo a educação científica como um caso particular, e nos perguntamos o que fazer para ter acesso a essas importantes percepções subjetivas sobre os fenômenos educacionais. A seguir, vimos como o século XX também levou filósofos a se debruçar sobre os possíveis meios de interação entre as subjetividades humanas (intersubjetividade), levando ao reconhecimento do importante papel da linguagem neste processo. Por fim, apresentamos as principais teses da Teoria do Agir Comunicativo, tentando mostrar que o relacionamento intersubjetivo (inclusive nas discussões dos fenômenos educacionais) estará tão mais presente em uma interação comunicativa quanto mais forem respeitadas certas regras pragmáticas de ação. Tentativas de fomento destas disposições de ação em contextos educativos ainda têm sido timidamente implementadas (GONÇALVES, 1999; CHAPANI e ORQUIZA-deCARVALHO, 2010; AZEVEDO, 2011), mas as pesquisas nesta área têm indicado bons resultados quando os participantes das discussões são encorajados a adotar as normas da teoria do Agir Comunicativo.

\section{Referências}

ALVES-MAZZOTTI, A. J.; GEWANDSZNAJDER, F. O Método nas Ciências Naturais e Sociais: Pesquisa Quantitativa e Qualitativa. 2a ed. São Paulo: Editora Pioneira, 2001.

ANDRADE, S. M. O.; TANAKA, O. Y. Interacionismo interpretativo: uma nova perspectiva teórica para as pesquisas qualitativas. Ensaios e Ciência: ciências biológicas, agrárias e da saúde, v. 5, n. 3, p. 55-71, 2001.

AZEVEDO, H. L. Competência Comunicativa de Futuros Professores Frente à Diversidade Religiosa na Abordagem do tema "Origens do Universo". [Dissertação de mestrado]. Faculdade de Ciências - Universidade Estadual Paulista, Bauru, 2011.

CHAPANI, D. T.; ORQUIZA-de-CARVALHO, L. M. Entre o sistema e o mundo da vida: possibilidades de ação comunicativa na trajetória formativa de professores de ciências. Práxis Educacional. Vitória da Conquista, v. 6, n. 9, p. 187-208, 2010.

CHAUI, M. Convite à filosofia. 13a ed. São Paulo: Editora Ática, 2006.

COMTE, A. Curso de Filosofia positiva. Coleção Os pensadores. São Paulo: Abril Cultural, 1973.

FEYERABEND, P. Contra o Método. São Paulo, Editora Unesp, 2011.

GAMBOA, S. S. Pesquisa em Educação: métodos e epistemologias. 2a ed. Chapecó: Argos, 2012.

GONÇALVES, M. A. S. Teoria da ação comunicativa de Habermas: Possibilidades de uma ação educativa de cunho interdisciplinar na escola. Educação \& Sociedade, ano XX, nº 66, p. 125-140, 1999.

HABERMAS, J. Racionalidade e comunicação. Lisboa: Edições 70, 2002.

Técnica e ciência como ideologia. Lisboa: Edições 70, 2007(a).

Entre naturalismo e religião. Rio de Janeiro: Tempo Brasileiro, 2007(b). 
HABERMAS, J. Teoria do Agir Comunicativo. São Paulo: Editora WMF Martins Fontes, 2012.

HUSSERL, E. A crise da humanidade europeia e a filosofia. Porto Alegre: EDIPUCRS, 2002.

KUHN, T. S. A estrutura das revoluções científicas. Tradução: B. V. Boeira e N. Boeira. São Paulo: Perspectiva, 2007.

LAKATOS, I. Oe falseamento e a metodologia dos programas de pesquisa. In: LAKATOS, I.; MUSGRAVE, A. A crítica e o desenvolvimento do conhecimento. São Paulo, Editora Cultrix, 1979.

OFFREDI, J. C. F. Uma proposta de democracia segundo Habermas: uma contribuição para concepção e análise do Direito. [Dissertação de mestrado]. Pontifícia Universidade Católica do Rio de Janeiro, Rio de Janeiro, 2006.

PEREIRA, J. R.; ARAÚJO, M. C. P. Concepções de ciência: uma reflexão epistemológica. Vidya, v. 29, n. 2, p. 57-70, 2009.

PÉREZ GÓMES, A. I. Compreender o ensino na escola: modelos metodológicos de investigação educativa. In: GIMENO SACRISTÁN, J.; PÉREZ GÓMES, A. I. Compreender e transformar o ensino. Porto Alegre: ArtMed, 1998.

POPPER, K. R. A lógica da pesquisa científica. São Paulo: Cultrix, 1993.

* Professor da Universidade Federal de Mato Grosso, Sinop, Mato Grosso, Brasil.

** Professora doutora da Universidade Federal de Mato Grosso, Sinop, Mato Grosso, Brasil.

\section{Correspondência}

Hernani Luiz Azevedo - Universidade Federal de Mato Grosso, ICNHS- Instituto de Ciências Naturais Humanas e Sociais. Avenida Alexandre Ferronato, 1200, Setor Industrial, CEP: 78557267 - Sinop, Mato Grosso - Brasil.

E-mail: hernaniazevedo@ufmt.br-gladysdw@gmail.com

Recebido em 03 de setembro de 2015

Aprovado em 25 de fevereiro de 2016 